\title{
Lack of association between peroxisome proliferator-activated receptors alpha and gamma2 polymorphisms and progressive liver damage in patients with non-alcoholic fatty liver disease: a case control study
}

\author{
Paola Dongiovanni ${ }^{1}$, Raffaela Rametta ${ }^{1}$, Anna Ludovica Fracanzani ${ }^{1}$, Luca Benedan ${ }^{1}$, Vittorio Borroni ${ }^{1}$, \\ Paolo Maggioni ${ }^{1}$, Marco Maggioni², Silvia Fargion', Luca Valenti ${ }^{{ }^{*}}$
}

\begin{abstract}
Background: Peroxisome proliferator-activated receptors (PPARs) play key roles in the pathogenesis of nonalcoholic fatty liver disease (NAFLD).

Aim: to assess the effect of functional single nucleotide polymorphisms (SNPS) of PPAR $\alpha$ and PPAR $\gamma 2$, previously associated with insulin resistance and dyslipidemia, on liver damage in NAFLD, whose progression is influenced by metabolic abnormalities and inherited factors.
\end{abstract}

Methods: The Leu162Val PPAR $\alpha$ and Pro12Ala PPAR 2 SNPs were evaluated by restriction analysis. We considered 202 Italian patients with biopsy-proven NAFLD.

Results: The frequency of the evaluated SNPs did not differ between patients and 346 healthy controls. The presence of the PPAR $\alpha 162 \mathrm{Val}$ allele (prevalence 57\%), but not of the PPAR 2 12Ala allele (prevalence 18\%), was associated with higher insulin resistance (HOMA-IR index $4.71 \pm 3.8$ vs. $3.58 \pm 2.7, p=0.026$ ), but not with hyperglycemia. The PPAR $\alpha 162 \mathrm{Val}$ and PPAR $\gamma 2$ 12Ala alleles were not associated with the severity of steatosis, necroinflammation, or fibrosis.

Conclusions: The presence of the PPAR $\alpha$ 162Val allele was associated with insulin resistance, but not with liver damage in NAFLD. Because of the limited power of the present sample, larger studies are needed to exclude a minor effect of the PPARY2 12Ala allele on necroinflammation/fibrosis in NAFLD.

\section{Background}

Nonalcoholic fatty liver disease (NAFLD), affecting 20$34 \%$ of the US and European populations [1,2], is considered the hepatic manifestation of the metabolic syndrome. NAFLD is characterized by hepatic insulin resistance [3], dyslipidemia [4], and is associated with increased mortality due to cardiovascular and liver diseases $[5,6]$.

\footnotetext{
* Correspondence: luca.valenti@unimi.it

${ }^{1}$ Metabolic Liver Diseases Research Center, Department of Internal Medicine, Università degli Studi di Milano, Fondazione Ospedale Policlinico "Ca' Granda" IRCCS, Milano, Italy

Full list of author information is available at the end of the article
}

Liver damage progression occurs when fatty liver is complicated by steatohepatitis (NASH) $[5,7,8]$, which is thought to be provoked by peripheral insulin resistance leading to an increased supply of free fatty acids (FFAs) to the liver, and resulting in oxidative, endoplasmic reticulum and cytokine mediated stress [9].

Inherited factors play a major role in the susceptibility to NAFLD. Indeed, 1) predisposition to NASH appears to cluster with that for metabolic risk factors within families, 2) ethnic differences, partially explained by a different prevalence of patatin-like phospholipase domain-contain 3 protein (PNPLA3) variants, have been reported [10-12], and 3) studies in twins demonstrated a 
high heritability of liver enzymes values reflecting liver fat content [13]. In addition, single nucleotide polymorphisms (SNPs) in genes involved in inflammation, oxidative stress, and fibrogenesis have been associated with the severity of NAFLD [14-19], and recently it has been demonstrated that SNPs influencing Insulin receptor activity predispose to liver damage in NAFLD, confirming that insulin resistance has a causative role in the progression of liver disease [20].

Peroxisome proliferator-activated receptor-alpha (PPAR $\alpha$ ) is a member of the nuclear hormone receptor superfamily, molecular target of long chain fatty acids, eicosanoids and fibrates (22), and it is expressed at high levels in tissues that catabolize fatty acids such as the liver, skeletal muscles, and the heart. PPAR $\alpha$ agonists lower plasma lipid levels, decrease intrahepatic and muscle lipid accumulation, normalize glucose and insulin levels, and reduce the risk of type 2 diabetes in rodent models [21-23]. It has been reported that PPAR $\alpha$ downregulation is involved in NASH pathogenesis by reducing FFAs catabolism [24]. Furthermore, the PPAR $\alpha$ agonists gemfibrozil and fenofibrate improve dyslipidemia and insulin sensitivity in humans [25]. Preliminary results indicate that another SNP in the PPAR $\alpha$ gene, the Val227Ala substitution, may also been implicated in the pathogenesis of NAFLD and could play a protective role against the development of obesity [26]. Since increased hepatic fat, the pathological hallmark of NAFLD, negatively influences insulin signaling [27] and is associated with activation of fibrogenesis [28], we hypothesized that the Leu162Val variant of $P P A R \alpha$, previously associated with decreased hepatic lipolysis, dyslipidemia and type 2 diabetes (table 1 ), could influence liver damage in NAFLD [29].

Peroxisome proliferator-activated receptor-gamma (PPAR $\gamma$ ), the molecular target of glitazones, is mainly known to regulate adipocytes differentiation and FFAs uptake and storage, and the PPAR $\gamma 2$ isoform is highly expressed in adipose tissue. PPAR $\gamma$ activation promotes adipogenesis, fatty-acid storage, and eventually obesity, insulin resistance, and type 2 diabetes. Pharmacological

\begin{tabular}{|c|c|c|c|c|}
\hline Gene & Function & Polymorphism & Effect & $\begin{array}{l}\text { Previous } \\
\text { association }\end{array}$ \\
\hline PPAR $\alpha$ & Induces lipolysis & $\begin{array}{l}\text { Lys162Val } \\
\text { (rs1800206) }\end{array}$ & - & $\begin{array}{l}\text { Insulin } \\
\text { resistance } \\
\text { Dyslipidemia } \\
\text { Diabetes [29] }\end{array}$ \\
\hline PPAR $\gamma 2$ & $\begin{array}{l}\text { Induces lipogenesis in } \\
\text { adipose tissue }\end{array}$ & $\begin{array}{l}\text { Pro12Ala } \\
\text { (rs1801282) }\end{array}$ & - & $\begin{array}{l}\text { Insulin } \\
\text { sensitivity } \\
{[32,40]}\end{array}$ \\
\hline
\end{tabular}

-: loss-of-function allele activation of PPAR $\gamma$ ameliorates insulin resistance in diabetes, and has been reported to decrease liver damage in NAFLD by restoring adipose tissue insulin sensitivity, thus decreasing FFAs flux to the liver [30,31]. The Pro12Ala SNP of PPAR 2 , which has been suggest to induce a modest impairment of transcriptional activation due to decreased DNA-binding affinity (table 1), was associated with decreased PPAR $\gamma$ activity in adipose tissue, and decreased insulin resistance and diabetes in Caucasians [32]. However, the effect of the Pro12Ala polymorphism on the risk of diabetes is still controversial [33]. As pharmacological modulation of PPAR $\gamma$ showed promising results on steatosis and necroinflammation in most, but not all, patients with NAFLD, whereas the effect on fibrosis is still undefined [30,34], we hypothesized that functional genetic variants may influence disease progression. In addition, the evaluation of the effect of inherited variability of PPAR 2 on liver damage progression may shed light on the possible long-term effects of treatment with $\mathrm{PPAR} \gamma$ agonists on liver fibrosis in NAFLD.

Aim of this study was to assess the effect of these well-characterized common functional PPAR $\alpha$ Leu162Val and PPAR 2 Pro12Ala SNPs on the severity of liver disease in a series of Italian patients with biopsy proven NAFLD.

\section{Methods}

\section{Subjects}

Informed written consent was obtained from each patient and control subject, and the study conforms to the ethical guidelines of the declaration of Helsinki.

Two hundred two consecutive Italian unrelated patients from Northern Italy with histologically proven NAFLD and available DNA samples, diagnosed between January 1999 and January 2007 were included. Other causes of liver disease were excluded, including increased alcohol intake (>30/20 g/day for M/F) [35], as confirmed by at least one family member and carboxydesialylated transferrin determination, $\mathrm{HBV}$ and $\mathrm{HCV}$ chronic viral hepatitis, autoimmune hepatitis, hereditary hemochromatosis, $\alpha 1$-antitrypsin deficiency, Wilson's disease, and drug induced liver disease. Metabolic parameters and fasting insulin levels, as determined by RIA, were available for each patient. Demographic and clinical features available are shown in table 2 .

The control group included 346 Italian subjects out of a larger series of 482 blood donors (71\%) of the same geographical origin of patients without clinical and biochemical evidence of liver and metabolic disease and no alcohol abuse. We excluded subjects with ALT > 30/18 $\mathrm{IU} / \mathrm{ml}$ in males/females [36], GGT > $35 \mathrm{IU} / \mathrm{ml}, \mathrm{BMI}>$ 28 , abdominal circumference $>100 \mathrm{~cm}$, glucose levels $\geq$ $100 \mathrm{mg} / \mathrm{dl}$, triglycerides $\geq 150 \mathrm{mg} / \mathrm{dl}$, or a fatty liver 
Table 2 Demographic and clinical features of patients with NAFLD and controls.

\begin{tabular}{lcc}
\hline & Italian controls & Italian adult NAFLD \\
\hline number & $\mathbf{3 4 6}$ & $\mathbf{2 0 2}$ \\
\hline Sex F & $74(21)$ & $41(20)$ \\
Age years & $47.7 \pm 12$ & $47.4 \pm 11$ \\
BMl Kg/m & $25.1 \pm 2.6^{*}$ & $27.4 \pm 3.8^{*}$ \\
Total cholesterol mg/dl & $194 \pm 34^{*}$ & $211 \pm 43^{*}$ \\
HDL cholesterol mg/dl & $56.2 \pm 13^{*}$ & $45.1 \pm 12^{*}$ \\
Triglycerides mg/dl & $89 \pm 43^{*}$ & $158 \pm 91^{*}$ \\
Fasting insulin IU/ml & $13.4 \pm 7^{*}$ & $16.8 \pm 11^{*}$ \\
Glucose mg/dl & $88.5 \pm 10^{*}$ & $98 \pm 24^{*}$ \\
HOMA-IR & $2.9 \pm 1.6^{*}$ & $4.1 \pm 3.3^{*}$ \\
ALT UI/ml & $23 \pm 9^{*}$ & $65 \pm 46^{*}$ \\
GGT UI/ml & $23 \pm 16^{*}$ & $87 \pm 96^{*}$ \\
Fibrosis stage F0/F1/F2/F3/F4 & - & $104 / 61 / 23 / 8 / 6$ \\
& & $(52 / 30 / 11 / 4 / 3)$ \\
\hline
\end{tabular}

${ }^{*} p<0.0001$ between Italian patients and controls, ():\% values

index $>35$, which has high specificity to rule out NAFLD in the general population [37]. Fasting insulin levels were available for 259 subjects.

\section{Histological assessment}

Tissue sections were stained with hematoxylin and eosin, impregnated with silver for reticulin framework, and stained with Periodic Acid-Schiff (PAS) for glycogen, Periodic Acid-Schiff diastase (DiPAS) for nonglycogen proteins, Perls for iron, and trichrome for collagen. A single expert pathologist unaware of clinical and genetic data reviewed biopsies. The presence and severity of NASH was assessed according to Kleiner et al. [38]. Briefly, histological activity (NAS: NAFLD activity score) is graded based on steatosis (0-3), lobular inflammation (0-3), and hepatocyte ballooning (0-2), whereas liver fibrosis is staged from 0 (absent) to 4 (cirrhosis). The minimum biopsy size was $1.7 \mathrm{~cm}$ and the number of portal areas 10 .

We chose as main outcome a fibrosis cut-off of stage $>1$ according to Kleiner et al. [38], in the attempt to identify patients with potentially progressive disease at an early stage [39].

\section{Genetic analysis}

DNA was extracted from peripheral blood by the phenol-chloroform method. Success rate in extracting DNA was $100 \%$ for each study group. $P P A R \alpha$ Leu 162 Val (rs1800206) and PPAR $\gamma 2$ Pro12Ala (rs1805192) SNPs were determined by restriction analysis, as previously described $[29,40]$ by personnel unaware of the subjects' clinical status. Moreover, the presence of specific polymorphic alleles as detected by restriction analysis was confirmed in each case by sequencing of random samples of patients. Samples from both NAFLD patients and controls have been included in each batch analyzed, and quality controls were performed to verify the reproducibility of the results. Valid genotypic data were obtained for $>99 \%$ of subjects analyzed. Subjects for whom incomplete clinical or genetic data were available were excluded from the analyses.

\section{Statistical analysis}

The sample size was calculated on the basis of the expected relative risk of the presence of a minor allele versus the wild-type allele, the desired power, and significance ( $\mathrm{p}<0.05$, two-tailed).

The sample size had a $99 \%$ and $75 \%$ power of detecting an OR of 1.5 for NAFLD for the presence of the PPAR $\alpha$ Leu162Val (rs1800206) and PPAR 2 Pro12Ala (rs1805192) SNPs, respectively, and a $100 \%$ and $83 \%$ power of detecting an OR of 2.0 for fibrosis $>1$ in patients with NAFLD, according to the observed genotype frequencies and liver damage distribution, for the presence of the PPAR $\alpha$ Leu162Val (rs1800206) and PPAR 2 Pro12Ala (rs1805192) SNPs, respectively (76\% and $33 \%$ power of detecting an OR of 1.5). Results are expressed as means \pm standard deviation and considered significant when $\mathrm{p}<0.05$ (two-tailed). Mean values were compared by t-test and by Wilcoxon test, as required. Frequencies were compared by Fisher's exact test.

To allow comparisons with the previous literature and due to the relatively low frequency of the minor alleles evaluated, the effect of genetic factors was tested under the assumption of a dominant effect. Analyses were carried out with JMP 6.0 statistical analysis software (SAS Institute Inc, Cary, NC).

\section{Results}

Clinical and genetic features of patients with NAFLD and controls

Despite similar age and sex distribution, as expected by enrolment criteria, patients with NAFLD had higher BMI, total cholesterol and triglycerides, lower HDL cholesterol, and higher insulin and HOMA-R index, ALT and GGT levels than controls (table 2).

The frequency distributions of the evaluated SNPs were not significantly different between Italian patients with NAFLD and controls (table 3). The genotype distribution of the polymorphic alleles was in Hardy-Weinberg equilibrium both in patients and controls.

\section{Effect of genetic factors on insulin resistance and metabolic features}

The effect of inherited factors on insulin resistance, evaluated by HOMA-R index, the presence of diabetes/ IFG, and HDL levels is shown in table 4. The PPAR $\alpha$ $162 \mathrm{Val}$ allele was nearly associated with higher HDL 
Table 3 Frequency distribution of evaluated gene polymorphisms in 202 Italian patients with NAFLD and 346 controls.

\begin{tabular}{lcccc}
\hline Gene & Genotype & Controls & Patients & P \\
\hline PPAR $\alpha$ & Lys162Lys & $137(40 \%)$ & $87(43 \%)$ & ns \\
(rs1800206) & Lys162Val & $159(46 \%)$ & $93(46 \%)$ & \\
& Val162Val & $50(14 \%)$ & $22(11 \%)$ & \\
\hline PPARy2 & Pro12Pro & $295(85 \%)$ & $166(82 \%)$ & ns \\
(rs1805192) & Pro12Ala & $50(14 \%)$ & $33(16 \%)$ & \\
& Ala12Ala & $1(1 \%)$ & $3(2 \%)$ & \\
& & & & \\
\hline
\end{tabular}

$P$ values are shown if $<0.1$.

ns: not significant

levels at univariate $(46.1 \pm 14$ vs. $43 \pm 10 \mathrm{mg} / \mathrm{dl}, \mathrm{p}=$ 0.051 ), but not at multivariate analysis, and patients positive for this allele had a trend for a higher prevalence of diabetes/IFG compared to those without (25\% vs. $16 \% ; \mathrm{p}=0.06)$. No significant effect on HDL levels and diabetes/IFG was observed for the PPAR 2 12Ala allele.

In patients with NAFLD, the PPAR $\alpha 162 \mathrm{Val}$ allele was significantly associated with higher HOMA-R (4.71 \pm 3.8 vs. $3.58 \pm 2.7, \mathrm{p}=0.026)$, and the association persisted after the exclusion of 9 diabetic patients treated with metformin $(4.8 \pm 3.8$ vs. $3.6 \pm 2.6 ; \mathrm{p}=0.04)$. We did not found any association between HOMA-R and the PPAR $\alpha$ SNP in controls subjects. In contrast, the $P P A R \gamma 2$ 12Ala allele had no effect on insulin resistance (Figure 1). The evaluated SNPs were not significantly associated with age, sex, BMI, the presence of hypertension, serum triglycerides, ALT, GGT, and ferritin levels, both in patients and in controls.

Effect of genetic factors on liver disease severity The effect of inherited factors on the severity of liver disease, evaluated as presence of severe histological

Table 4 Metabolic parameters of patients with NAFLD subdivided according to the presence or absence of the PPAR $\alpha 162$ Val and PPAR $\gamma 2$ 12Ala alleles.

\begin{tabular}{ccccc}
\hline & & \multicolumn{2}{c}{ Polymorphic allele } & \\
\cline { 3 - 4 } & Gene & Present & Absent & p \\
\hline \multirow{2}{*}{ PPAR $\alpha$} & HDL & $46.1 \pm 14$ & $43 \pm 10$ & 0.051 \\
& Homa-R & $4.5 \pm 3.7$ & $3.6 \pm 2.7$ & 0.026 \\
& Diabetes/IGT & $40(25)$ & $19(16)$ & 0.060 \\
\hline PPAR 2 & HDL & $50.7 \pm 14$ & $49.4 \pm 14$ & $\mathrm{~ns}$ \\
& Homa-R & $4.1 \pm 2.1$ & $4.1 \pm 3.5$ & $\mathrm{~ns}$ \\
\hline & Diabetes/IGT & $8(18)$ & $51(22)$ & $\mathrm{ns}$ \\
\hline
\end{tabular}

$P$ values are shown if $<0.1$.

():\% values, ns: not significant.

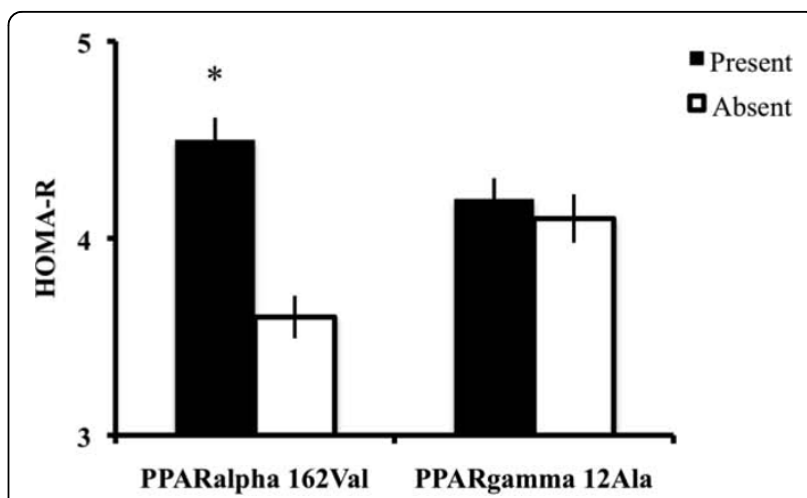

Figure 1 HOMA-R index in 202 patients with non-alcoholic fatty liver disease (NAFLD) subdivided according to the presence or absence of the PPAR $\alpha 162 \mathrm{Val}$ and PPAR $\gamma 2$ 12Ala SNPs.

activity (NAS $>5$ ) and of severe fibrosis (Kleiner $>1$ ), is shown in figure 2 and 3 respectively. No significant effect of the PPAR $\alpha 162 \mathrm{Val}$ and PPAR $\gamma 2$ 12Ala alleles was observed on liver damage. The prevalence of NAS > 5 was similar between patients positive and negative for the PPAR $\alpha 162 \mathrm{Val}$ allele ( $6 \%$ vs. $8 \% ; \mathrm{p}=\mathrm{ns}$ ). In patients positive for the PPAR 22 12Ala allele, the prevalence of NAS > 5 was lower compared to that observed in negative patients ( $3 \%$ vs. $8 \% ; \mathrm{p}=\mathrm{ns}$ ). Although the PPAR 2 12Ala allele was associated with a lower prevalence of severe histological activity, the sample size is too small to cross the statistical significance threshold. The prevalence of fibrosis > 1 was $22 \%$ in patients positive for $P P A R \alpha 162 \mathrm{Val}$ and $14 \%$ in those negative for this allele ( $\mathrm{p}=\mathrm{ns}$ ). Also for the PPAR $\gamma 2 \mathrm{SNP}$, the prevalence of fibrosis $>1$ was similar in patients carrying the $12 \mathrm{Ala}$ allele compared to the negative ones $(19 \%$ vs. $18 \%$; p = ns).



Figure 2 Prevalence of severe histological activity (NASH activity score (NAS) $>5$ ) in 202 biopsied patients with nonalcoholic fatty liver disease (NAFLD), subdivided according to the presence or absence of the PPAR $\alpha 162 \mathrm{Val}$ and PPAR 2 12Ala SNPs. 




Figure 3 Prevalence of fibrosis stage $>1$ in 202 biopsied patients with non-alcoholic fatty liver disease (NAFLD), subdivided according to the presence or absence of the PPAR $\alpha$ 162Val and PPARY2 12Ala SNPs.

Adjustment for age, BMI, ALT levels and diabetes/ IGT did not modify the lack of association between the evaluated SNPs and liver damage.

\section{Discussion}

In this paper, we evaluated the effect of well-characterized, functional, common SNPs of genes involved in the regulation of lipid metabolism, and which are amenable of pharmacologic modulation, on the severity of liver injury in patients with NAFLD. Our results, obtained in the largest series of well characterized patients with liver histology available to date, indicate that the PPAR $\alpha$ $162 \mathrm{Val}$ allele is associated with insulin resistance but not with liver damage, whereas the PPAR 2 12Ala SNP is neither associated with insulin resistance nor with liver damage.

Since NAFLD is considered the hepatic expression of metabolic syndrome, and has a strong genetic component $[11,12]$, we reasoned that genetic factors influencing lipid metabolism might predispose to progressive liver disease in affected subjects $[27,29,32]$. PPARs, because of 1 ) their key role in NAFLD pathogenesis 2) genetic variability determining altered function 3 ) are targets of approved drugs, represent ideal candidate genes.

We preliminarily compared the distribution of PPARs SNPs in Italian patients with NAFLD and healthy controls with normal liver enzymes [36] and absence of metabolic alterations. Even if our sample size had a good power of detecting a $50 \%$ increased risk of NAFLD for the presence of the evaluated genetic factors, the prevalence of the SNPs did not differ between patients and controls, suggesting that they do not represent a risk factor for NAFLD. However, we cannot exclude that these genetic variants may influence the risk of NAFLD in patients carrying acquired risk factors, such as obesity, or that other rarer and less characterized variants of these genes may be associated with NAFLD [26].

Indeed, due to the very strict selection criteria our control subjects had no metabolic risk factors and a low fatty liver index, but we did not get direct evidence of the absence of mild fatty liver disease, which may occur even in absence of the metabolic syndrome and abnormal liver function test. Notwithstanding, the main goal of this study was to ascertain whether PPARs SNPs affected the severity of liver disease in patients with biopsy proven NAFLD.

The 162 Val PPAR $\alpha$ SNP is a loss-of-function allele that has been associated with decreased hepatic lipolysis, dyslipidemia and progression of type 2 diabetes (22). Results indicated that the $162 \mathrm{Val}$ SNP, present in $57 \%$ of the patients, was associated with increased insulin resistance in patients but not in controls, suggesting a possible interaction between liver fat and the PPAR $\alpha$ $162 \mathrm{Val}$ allele in the pathogenesis of insulin resistance. Indeed, this genetic variant is supposed to increase insulin resistance and liver fat content by reducing PPAR $\alpha$ driven lipolysis, potentially explaining our findings (22). The biological function of this nuclear receptor may also account for the lack of association with hepatic damage despite heightened insulin resistance [41]. Indeed, fatty acid oxidation, contrasted by the $162 \mathrm{Val}$ allele, represents a major source of reactive oxygen species that trigger lipoperoxidation in NAFLD [9]. Thus, in patients with the $162 \mathrm{Val}$ allele the risk related to increased insulin resistance may be balanced by the protective effect of decreased oxidative stress.

The 12Ala PPAR 2 SNP is a loss-of-function allele that been associated with decreased PPAR $\gamma$ activity in adipose tissue, decreased insulin resistance and diabetes in Caucasians [32]. The 12Ala allele, present in $18 \%$ of NAFLD patients, was neither associated with liver damage nor with insulin sensitivity. The lack of association between PPAR 2 SNP and insulin resistance is possibly related to a prevalent effect of this gene on insulin resistance in tissues different from the liver. We cannot exclude that the evaluated genetic factors may confer a small increase (less than 1.5-fold and 2-fold for the $P P A R \alpha$ and PPAR 22 SNPs, respectively, a threshold for which we had a very good power to detect an association with progressive disease) in the risk of progressive disease, but a larger sample is required to verify this hypothesis. However, the possible effect would be much less strong than that exerted by other genetic variants, such as those influencing insulin receptor signaling and the PNPLA3 rs738409 SNP, which were significantly associated with liver fibrosis in the same series $[42,43]$.

We believe that the high relevance of these two PPARs genes for the pathogenesis of liver damage in 
$\mathrm{NASH}$, and the clinical, although still investigational and off-label, use of PPAR $\gamma$ agonists to treat NASH, requires a deeper knowledge of the relationship between these two genes and NAFLD. Since it is possible that these SNPs may confer a small increase in the risk of NASH progression, which could not be detected by the sample size of this study (this is especially true for the $P P A R \gamma 2$ SNP, due to the lower prevalence), we suggest that the issue could be addressed by meta-analysis of the present and future reports. In addition, as we are moving towards individualized medicine, these data could provide the basis to design pharmacogenetic studies to address whether the therapeutic efficacy of PPAR $\gamma$ agonists in patients NASH is affected by the PPAR 2 12Ala SNP. Noteworthy, the effect of the Pro12Ala SNP on diabetes risk is still controversial. Indeed, some Authors have reported that, in contrast to previous reports, the Ala12 allele protects against the development of diabetes $[44,45]$, so that the observed trend for a decreased NAS activity in patients carrying the 12Ala allele may reflect a reduced risk for progressive liver damage in subjects carrying this genetic variant, although the difference was not significant due to the insufficient power of the study. This interpretation would be consistent with a protective effect of PPAR $\gamma$ agonists on histological activity, despite the lack of association between the PPAR 2 12Ala SNP and insulin resistance in the present series of patients with NAFLD.

\section{Conclusions}

In conclusion, this study indicates that the presence of the PPAR $162 \mathrm{Val}$ and PPAR 2 12Ala SNPs influencing lipid metabolism and insulin sensitivity is not a major determinant of progressive liver damage in Caucasian patients with NAFLD. In addition, our data suggest that insulin resistance does not always translate in fibrosis, in that patients carrying the PPAR $\alpha$ Pro12Ala SNP had increased insulin resistance without different severity of liver damage, and that the genetic background underlying metabolic abnormalities has a major role in determining the clinical outcome [42].

\section{List of abbreviations}

NAFLD: nonalcoholic fatty liver disease; NAS: NAFLD activity score; NASH: nonalcoholic steatohepatitis; SNPs: single nucleotide polymorphisms; PPARs: Peroxisome proliferator-activated receptors.

\section{Acknowledgements}

We thank E Fatta, C Bertelli, and D Bignamini for clinical assistance. Grant support: The work was supported by the following grants: FIRST Università di Milano 2007, 2008 (LV); Ricerca corrente Ospedale Maggiore Policlinico 2006 and 2008 (LV); and Centro per lo Studio delle Malattie del Fegato e del Metabolismo.

\section{Author details}

${ }^{1}$ Metabolic Liver Diseases Research Center, Department of Internal Medicine, Università degli Studi di Milano, Fondazione Ospedale Policlinico "Ca' Granda" IRCCS, Milano, Italy. Department of Pathology, Fondazione Ospedale Policlinico Ca' Granda ed Ospedale San Paolo IRCCS, Milano, Italy.

\section{Authors' contributions}

PD and LV designed the study, analyzed and interpreted data, and wrote the manuscript, LV and SF funded the study, PD, RR, LB, VB processed the biological samples and performed the genetic analyses, PM and ALF collected and evaluated clinical data, MM reviewed liver biopsies, all Authors read, edited, and approved the final version of the manuscript.

\section{Authors' information}

PD is a senior research fellow and LV assistant professor at the Metabolic Liver Diseases Center, University of Milan, Policlinic Hospital, directed by professor SF. They have contributed with several manuscripts to the field of NASH genetics.

\section{Competing interests}

The authors declare that they have no competing interests.

Received: 1 May 2010 Accepted: 8 September 2010

Published: 8 September 2010

\section{References}

1. Browning JD, Szczepaniak LS, Dobbins R, Nuremberg P, Horton JD, Cohen JC, Grundy SM, Hobbs HH: Prevalence of hepatic steatosis in an urban population in the United States: impact of ethnicity. Hepatology 2004, 40(6):1387-1395.

2. Bellentani S, Saccoccio G, Masutti F, Croce LS, Brandi G, Sasso F, Cristanini G, Tiribelli C: Prevalence of and risk factors for hepatic steatosis in Northern Italy. Ann Intern Med 2000, 132(2):112-117.

3. Marchesini G, Brizi M, Bianchi G, Tomassetti S, Bugianesi E, Lenzi M, McCullough AJ, Natale S, Forlani G, Melchionda N: Nonalcoholic fatty liver disease: a feature of the metabolic syndrome. Diabetes 2001, 50(8):1844-1850

4. Targher G, Bertolini L, Padovani R, Rodella S, Zoppini G, Zenari L, Cigolini M, Falezza G, Arcaro G: Relations between carotid artery wall thickness and liver histology in subjects with nonalcoholic fatty liver disease. Diabetes Care 2006, 29(6):1325-1330.

5. Ekstedt M, Franzen LE, Mathiesen UL, Thorelius L, Holmqvist M, Bodemar G, Kechagias S: Long-term follow-up of patients with NAFLD and elevated liver enzymes. Hepatology 2006, 44(4):865-873.

6. Bugianesi E, Leone N, Vanni E, Marchesini G, Brunello F, Carucci P, Musso A, De Paolis P, Capussotti L, Salizzoni M, et al: Expanding the natural history of nonalcoholic steatohepatitis: from cryptogenic cirrhosis to hepatocellular carcinoma. Gastroenterology 2002, 123(1):134-140.

7. Villanova N, Moscatiello S, Ramilli S, Bugianesi E, Magalotti D, Vanni E, Zoli M, Marchesini G: Endothelial dysfunction and cardiovascular risk profile in nonalcoholic fatty liver disease. Hepatology 2005, 42(2):473-480.

8. Marchesini G, Bugianesi E, Forlani G, Cerrelli F, Lenzi M, Manini R, Natale S, Vanni E, Villanova N, Melchionda N, et al: Nonalcoholic fatty liver, steatohepatitis, and the metabolic syndrome. Hepatology 2003, 37(4):917-923

9. Day CP: From fat to inflammation. Gastroenterology 2006, 130(1):207-210.

10. Romeo S, Kozlitina J, Xing C, Pertsemlidis A, Cox D, Pennacchio LA Boerwinkle E, Cohen JC, Hobbs HH: Genetic variation in PNPLA3 confers susceptibility to nonalcoholic fatty liver disease. Nat Genet 2008.

11. Willner IR, Waters B, Patil SR, Reuben A, Morelli J, Riely CA: Ninety patients with nonalcoholic steatohepatitis: insulin resistance, familial tendency, and severity of disease. Am J Gastroenterol 2001, 96(10):2957-2961.

12. Wilfred de Alwis NM, Day CP: Genetics of alcoholic liver disease and nonalcoholic fatty liver disease. Semin Liver Dis 2007, 27(1):44-54.

13. Makkonen J, Pietilainen KH, Rissanen A, Kaprio J, Yki-Jarvinen H: Genetic factors contribute to variation in serum alanine aminotransferase activity independent of obesity and alcohol: a study in monozygotic and dizygotic twins. J Hepatol 2009, 50(5):1035-1042.

14. Valenti L, Dongiovanni P, Piperno A, Fracanzani AL, Maggioni M, Rametta R, Loria $P$, Casiraghi MA, Suigo E, Ceriani $R$, et al: alpha1-Antitrypsin 
mutations in NAFLD: High prevalence and association with altered iron metabolism but not with liver damage. Hepatology 2006, 44(4):857-864.

15. Valenti L, Fracanzani AL, Dongiovanni P, Santorelli G, Branchi A, Taioli E, Fiorelli G, Fargion S: Tumor necrosis factor alpha promoter polymorphisms and insulin resistance in nonalcoholic fatty liver disease. Gastroenterology 2002, 122(2):274-280.

16. Dixon JB, Bhathal PS, Jonsson JR, Dixon AF, Powell EE, O'Brien PE: Profibrotic polymorphisms predictive of advanced liver fibrosis in the severely obese. J Hepatol 2003, 39(6):967-971.

17. Namikawa C, Shu-Ping Z, Vyselaar JR, Nozaki Y, Nemoto Y, Ono M, Akisawa N, Saibara T, Hiroi M, Enzan H, et al: Polymorphisms of microsomal triglyceride transfer protein gene and manganese superoxide dismutase gene in non-alcoholic steatohepatitis. $J$ Hepatol 2004, 40(5):781-786

18. Miele L, Beale G, Patman G, Nobili V, Leathart J, Grieco A, Abate M, Friedman SL, Narla G, Bugianesi E, et al: The Kruppel-like factor 6 genotype is associated with fibrosis in nonalcoholic fatty liver disease. Gastroenterology 2008, 135(1):282-291, e281.

19. Song J, da Costa KA, Fischer LM, Kohlmeier M, Kwock L, Wang S, Zeisel SH: Polymorphism of the PEMT gene and susceptibility to nonalcoholic fatty liver disease (NAFLD). FASEB J 2005, 19(10):1266-1271.

20. Dongiovanni P: Genetic variants regulating insulin receptor signalling are associated with the severity of liver damage in patients with nonalcoholic fatty liver disease. Gut 2010.

21. JM Y: Peroxisome proliferators-activated receptor (PPAR)-alpha activation lowers muscle lipids and improves insulin sensitivity in high fat-fed rats: comparison with PPAR-gamma activation. Diabetes 2001, 50:411-417.

22. H K: Peroxisome proliferators-activated receptor-alpha agonist treatment in a transgenic model of type 2 diabetes reverses the lipotoxic state and improves glucose homeostasis. Diabetes 2003, 52:1770-1778.

23. Guerre-Millo : Peroxisome proliferator-activated receptor alpha activators improve insulin sensitivity and reduce adiposity. J Biol Chem 2000, 275:16638-16642.

24. Stienstra R, Saudale F, Duval C, Keshtkar S, Groener JE, van Rooijen N, Staels B, Kersten S, Muller M: Kupffer cells promote hepatic steatosis via interleukin-1 beta-dependent suppression of peroxisome proliferatoractivated receptor alpha activity. Hepatology 51(2):511-522.

25. L M: Effects of gemfibrozil on insulin sensitivity and on haemostatic variables in hypertriglyceridemic patients. Atherosclerosis 2000 148:397-406

26. Chen S, Li Y, Li S, Yu C: A Val227Ala substitution in the peroxisome proliferator activated receptor alpha (PPAR alpha) gene associated with non-alcoholic fatty liver disease and decreased waist circumference and waist-to-hip ratio. J Gastroenterol Hepatol 2008, 23(9):1415-1418.

27. Samuel VT, Liu ZX, Wang A, Beddow SA, Geisler JG, Kahn M, Zhang XM, Monia BP, Bhanot S, Shulman GI: Inhibition of protein kinase Cepsilon prevents hepatic insulin resistance in nonalcoholic fatty liver disease. $J$ Clin Invest 2007, 117(3):739-745.

28. Chalasani N, Wilson L, Kleiner DE, Cummings OW, Brunt EM, Unalp A: Relationship of steatosis grade and zonal location to histological features of steatohepatitis in adult patients with non-alcoholic fatty liver disease. J Hepatol 2008, 48(5):829-834.

29. Flavell DM, Ireland H, Stephens JW, Hawe E, Acharya J, Mather H, Hurel SJ, Humphries SE: Peroxisome proliferator-activated receptor alpha gene variation influences age of onset and progression of type 2 diabetes. Diabetes 2005, 54(2):582-586.

30. Belfort R, Harrison SA, Brown K, Darland C, Finch J, Hardies J, Balas B, Gastaldelli A, Tio F, Pulcini J, et al: A placebo-controlled trial of pioglitazone in subjects with nonalcoholic steatohepatitis. N Engl I Med 2006, 355(22):2297-2307.

31. Gastaldelli A, Harrison SA, Belfort-Aguilar R, Hardies LJ, Balas B, Schenker S, Cusi K: Importance of changes in adipose tissue insulin resistance to histological response during thiazolidinedione treatment of patients with nonalcoholic steatohepatitis. Hepatology 2009, 50(4):1087-1093.

32. Tonjes A, Scholz M, Loeffler M, Stumvoll M: Association of Pro12Ala polymorphism in peroxisome proliferator-activated receptor gamma with Pre-diabetic phenotypes: meta-analysis of 57 studies on nondiabetic individuals. Diabetes Care 2006, 29(11):2489-2497.

33. Altshuler $D$, Hirschhorn JN, Klannemark $M$, Lindgren $C M$, Vohl MC, Nemesh J, Lane CR, Schaffner SF, Bolk S, Brewer C, et al: The common
PPARgamma Pro12Ala polymorphism is associated with decreased risk of type 2 diabetes. Nat Genet 2000, 26(1):76-80.

34. Bugianesi E, Gentilcore E, Manini R, Natale S, Vanni E, Villanova N, David E, Rizzetto M, Marchesini G: A randomized controlled trial of metformin versus vitamin $\mathrm{E}$ or prescriptive diet in nonalcoholic fatty liver disease. Am J Gastroenterol 2005, 100(5):1082-1090.

35. Bellentani STC, Saccoccio G, Sodde M, Fratti N, De Martin C, Cristianini G: Prevalence of chronic liver disease in the general population of northern Italy: the Dionysos Study. Hepatology 1994, 20(6):1442-1449.

36. Prati D, Taioli E, Zanella A, Della Torre E, Butelli S, Del Vecchio E, Vianello L, Zanuso F, Mozzi F, Milani S, et al: Updated definitions of healthy ranges for serum alanine aminotransferase levels. Ann Intern Med 2002, 137(1):1-10.

37. Bedogni G, Bellentani S, Miglioli L, Masutti F, Passalacqua M, Castiglione A, Tiribelli C: The Fatty Liver Index: a simple and accurate predictor of hepatic steatosis in the general population. BMC Gastroenterol 2006, 6:33.

38. Kleiner DE, Brunt EM, Van Natta M, Behling C, Contos MJ, Cummings OW, Ferrell LD, Liu YC, Torbenson MS, Unalp-Arida A, et al: Design and validation of a histological scoring system for nonalcoholic fatty liver disease. Hepatology 2005, 41(6):1313-1321.

39. Angulo P, Hui JM, Marchesini G, Bugianesi E, George J, Farrell GC, Enders F, Saksena $S$, Burt AD, Bida JP, et al: The NAFLD fibrosis score: a noninvasive system that identifies liver fibrosis in patients with NAFLD. Hepatology 2007, 45(4):846-854.

40. Yen CJ, Beamer BA, Negri C, Silver K, Brown KA, Yarnall DP, Burns DK, Roth J, Shuldiner AR: Molecular scanning of the human peroxisome proliferator activated receptor gamma (hPPAR gamma) gene in diabetic Caucasians: identification of a Pro12Ala PPAR gamma 2 missense mutation. Biochem Biophys Res Commun 1997, 241(2):270-274.

41. Wieckowska A, Zein NN, Yerian LM, Lopez AR, McCullough AJ, Feldstein AE: In vivo assessment of liver cell apoptosis as a novel biomarker of disease severity in nonalcoholic fatty liver disease. Hepatology 2006 44(1):27-33.

42. Dongiovanni P, Valenti L, Rametta R, Daly AK, Nobili V, Mozzi E, Leathart J, Pietrobattista A, Burt AD, Maggioni M, et al: Genetic variants regulating Insulin Receptor signaling are associated with the severity of liver damage in patients with nonalcoholic fatty liver disease. Gut 2010, 59:267-273.

43. Valenti L, Al-Serri A, Daly AK, Galmozzi E, Rametta R, Dongiovanni P, Nobili V, Mozzi E, Roviaro G, Vanni E, et al: Homozygosity for the PNPLA3/ adiponutrin I148 M polymorphism influences liver fibrosis in patients with nonalcoholic fatty liver disease. Hepatology 2010, , 51: 1209-1217.

44. Buzzetti R, Petrone A, Ribaudo MC, Alemanno I, Zavarella S, Mein CA, Maiani F, Tiberti C, Baroni MG, Vecci E, et al: The common PPAR-gamma2 Pro12Ala variant is associated with greater insulin sensitivity. Eur J Hum Genet 2004, 12(12):1050-1054

45. Hara K, Okada T, Tobe K, Yasuda K, Mori Y, Kadowaki H, Hagura R, Akanuma Y, Kimura S, Ito C, et al: The Pro12Ala polymorphism in PPAR gamma2 may confer resistance to type 2 diabetes. Biochem Biophys Res Commun 2000, 271(1):212-216.

\section{Pre-publication history}

The pre-publication history for this paper can be accessed here: http://www.biomedcentral.com/1471-230X/10/102/prepub

\section{doi:10.1186/1471-230X-10-102}

Cite this article as: Dongiovanni et al: Lack of association between peroxisome proliferator-activated receptors alpha and gamma2 polymorphisms and progressive liver damage in patients with nonalcoholic fatty liver disease: a case control study. BMC Gastroenterology 2010 10:102. 